\title{
AS MÚLTIPLAS DIMENSÕES DA EDUCAÇÃO AMBIENTAL: POR UMA AMPLIAÇÃO DA ABORDAGEM
}

\section{The multiple dimensions of environmental education: towards an approach expansion}

\author{
Djalma Ferreira Pelegrini \\ Doutorado em Geografia (UFU) \\ Pesquisador - Empresa de Pesquisa Agropecuária de Minas Gerais - EPAMIG \\ Uberlândia/MG - Brasil \\ djalma@epamig.br \\ Vânia Rúbia Farias Vlach \\ Dra. em Geopolítica \\ Pesquisador Produtividade em Pesquisa-PQ / CNPq \\ Uberlândia/MG - Brasil \\ vaniarubiavlach@yahoo.com.br
}

Artigo recebido para publicação em 07/02/2011 e aceito para publicação em 04/07/2011

RESUMO: Tendo em vista os desafios propostos aos professores, e considerando as peculiaridades da sociedade moderna e industrial, o presente artigo aborda a temática da educação ambiental no Brasil. As discussões sobre a problemática ambiental raramente conseguem alcançar o plano do ensino escolar, em nível fundamental e médio, fazendo persistir a distância entre universidade e escola de formação básica, entre debate acadêmico acerca da problemática ambiental e educação ambiental. O tema da conservação ambiental não é apenas um desafio didático-pedagógico, como vem sendo tratado por muitos educadores, mas diz respeito a uma problemática muito mais complexa. O trabalho tem como objetivo discutir a necessidade de ampliação da discussão, de maneira que possibilite o tratamento de temas fundamentais, geralmente discutidos no campo da política, da economia, e da sociologia, como estratégia de sensibilização e compreensão da problemática ambiental. A pesquisa foi conduzida a partir da análise dos condicionantes da problemática ambiental, e do estudo do processo de incorporação da temática ambiental nas disciplinas do grupo das ciências sociais. Como resultado, a crise ambiental é entendida como mais um sintoma da crise da modernidade, que se manifesta não apenas por intermédio do desajuste ambiental, mas também por meio do agravamento dos problemas sociais, políticos e econômicos.

Palavras-chave: Educação Ambiental. Modernidade. Ambiente.

ABSTRACT: Considering the challenges proposed for teachers, and the peculiarities of modern and industrial society, this article approaches the theme of environmental education in Brazil. Discussions about the environment problem seldom reach the teaching level, on the basic and intermediary levels, maintaining the gap between the university and the basic formation school, between the academic debate about the environment problematic and environmental education. The theme environment conservation is not only a didactical-pedagogical challenge, as it has been treated by many educators, but is related to a much more complex problem. This study has as objective to discuss the need to expand the discussion in such a way that it would allow the treatment of fundamental themes, generally discussed in politics, economy, sociology, as an awareness and comprehension of environment problematic strategy. The research was 
done from the analysis of environment problematic conditionings, and the study of the process of incorporation of the environment theme in courses of the social sciences group. As a result, the environment crisis is understood more as a symptom of the modernity crisis, which is manifested not only through the environment disadjustment, but also by the worsening of social, political and economical problems.

Keywords: Environmental education. Modernity. Environment.

\section{INTRODUÇ̃̃O}

Dentre os grandes desafios que se apresentam aos professores de todos os níveis do ensino, a educação ambiental talvez esteja entre os mais complexos. A constituição da sociedade industrial no ocidente, a partir do século XVIII, concomitante a simultâneos processos modernizantes, engendrou um turbilhão de desajustes econômicos, políticos e sociais, grandemente explorados pelo pensamento social nos últimos duzentos anos. Contudo, o debate acerca das consequências do desenvolvimento tecnológico e industrial sobre a natureza, em geral circunscrito às comunidades acadêmicas, foi ainda mais dificultado pela disjunção dos campos de pesquisa, que tem limitado o diálogo entre os pesquisadores.

As discussões sobre a problemática ambiental raramente conseguem alcançar o plano do ensino escolar, em nível fundamental e médio, fazendo persistir a distância entre universidade e escola de formação básica, entre debate acadêmico acerca da problemática ambiental e educação ambiental. O tema da conservação ambiental é, como veremos, não apenas um desafio didático-pedagógico - como vem sendo tratado por muitos educadores - mas também um problema de caráter econômico, político, social e ideológico.

Tendo em vista estas temáticas, este artigo inicia com o tratamento de alguns problemas na esfera da educação ambiental. A seguir, aborda tópicos relacionados à organização dos saberes, face à verificação de que o acertado equacionamento da problemática ambiental só pode ser realizado em um quadro mais amplo.

\section{DESAFIOS DA EDUCAÇÃO AMBIENTAL NA SOCIEDADE DE CONSUMO}

Da polarização das ciências em dois blocos distintos (de um lado as ciências naturais e de outro as humanidades), sucedeu uma conceituação de ambiente restrita a uma concepção naturalista e cientificista - um enfoque ecológico -, em que os elementos componentes do quadro natural (ar, água, solo, plantas e animais etc.) situavam-se hierarquicamente em posição mais importante do que o homem socialmente organizado (MENDONÇA, 2002).

É no contexto do agravamento da crise ambiental, durante o século XX, que a reconceituação de ambiente foi requerida, face à percepção de que os danos provocados à natureza pela humanidade resultam de uma variedade de transformações associadas à modernização. Não apenas os fenômenos técnico-industriais e a ação das corporações e do Estado são responsáveis pela difusão de novos padrões de consumo e pelo estabelecimento de um estilo de vida moderno, predominantemente urbanizado. É necessário também considerar a interferência dos meios de comunicação, como agentes conformadores de uma cultura de massas.

Esta compreensão não implica, porém, na redução dos elementos da natureza a meros recursos, pois como ressaltou Mendonça (2002), "antes de serem transformados constituem-se em bens e elementos naturais que possuem dinâmica própria e que independem da apropriação social [...]" (MENDONÇA, 2002, p. 138).

Portanto, o primeiro passo, efetuado nos últimos anos, a caminho da sensibilização da sociedade em relação aos problemas ambientais, exigiu a ampliação do conceito de ambiente. Esta adequação do conceito, ainda em processo no seio das comunidades de estudiosos, em função de sua própria heterogeneidade, apresenta-se, para Mendonça (2002, p.125-126), como um desafio "para toda uma geração de intelectuais, cientistas e ambientalistas que se encontram 
vinculados a tais discussões no presente, e certamente também no futuro próximo", e diz respeito à inserção, na abordagem ambiental, da perspectiva humana portanto social, econômica, política e cultural.

A reconceituação de ambiente promoveu a aproximação de sentido dos termos "meio" e "ambiente", de maneira que a expressão "meio ambiente" parece comportar uma redundância. De fato, foi Maximilien Sorre, em um texto escrito em 1954 - ' $L$ ' adaptation au milieu climatique et bio-social. Géographie psychologique." - quem adiantou: "na prática (o termo meio) tem o mesmo valor que ambiente ou meio ambiente" (SORRE, 1984.). Para ele, o termo meio "refere-se ao conjunto das condições exteriores de vida do indivíduo ou do grupo". Sentido semelhante toma o termo "ambiente" quando nele incluímos, além dos elementos do quadro natural - bióticos e abióticos -, os aspectos propriamente humanos: sócioculturais, econômicos e políticos.

No mesmo texto, Max. Sorre afirma que, no final do século XIX "era marcante a tendência de reduzir o meio aos seus elementos materiais" (SORRE, 1984, p. 32), tendência que pôde ser verificada, mais tardiamente, relativamente à noção de ambiente.

A reconceituação de ambiente constituiu-se numa etapa essencial na tentativa de equacionamento da questão ambiental. Primeiro, por incluir aspectos que extrapolam a perspectiva naturalista, aludindo aos padrões modernos de produção e consumo adotados pela civilização industrial e à própria ordem social, econômica e política estabelecida. Segundo, a reconceituação de ambiente deixa explícito que o tratamento da questão ambiental trará resultados pífios se permanecer restrito ao discurso pedagógico e desconsiderar a luta política e ideológica que vem sendo travada, no mais das vezes, por motivos econômicos e estratégicos, segundo interesses de corporações e Estados hegemônicos, em nível planetário.

Não se trata de negar a necessidade e a urgência de uma ação educativa em prol de uma consciência solidária, capaz de promover o enfrentamento de questões como a racionalização do uso da água, o cuidado com o lixo, etc., problemas que têm, na maioria das vezes, origem local ou regional. Entretanto, se não levarmos em conta a interferência dos fatores econô- micos, sociais e culturais, os resultados no campo da educação serão muito pequenos.

Além disso, parece claro que as necessárias transformações no ensino não se farão de maneira isolada - independente das demais transformações em pauta - no contexto de uma sociedade autoritária, em que o poder político age, prioritariamente, em favor dos grupos econômicos dominantes, e não para promoção da justiça social. A educação ambiental, por conseguinte, não se fará desligada de uma educação completa.

É importante compreender que o planejamento de ações destinadas a sensibilizar o educando no tocante à problemática ambiental requer um questionamento a respeito dos padrões de consumo e produção importados dos países ricos, e por nós adotados sob a influência ideológica dos meios de comunicação de massa a serviço dos grupos dominantes, nacionais e estrangeiros, geralmente imbricados uns com os outros.

É necessário por em causa a ideologia produtivista que se instalou no ocidente desde o século XIX, resultante da difusão do modelo de desenvolvimento mecanoprodutivista (LABEYRI, 2002), em que a intensificação do aporte de capital de investimentos (visando promover o aumento dos lucros com a venda de mercadorias) impele o aumento crescente da produção e do consumo. A contradição entre crescimento do consumo (condição de permanência do modelo econômico) e a preservação ambiental manifesta-se claramente neste processo, já que ele corresponde, de fato, à intensificação dos processos de produção destrutiva.

Em um contexto em que o pretenso progresso sociocultural resulta do aumento da produção e do consumo, coube um papel fundamental aos pesquisadores, qual seja, a partir da geração de conhecimentos que conduzem à dominação técnica da natureza, permitir a exploração "racional" dos recursos - dominar para explorar (SANTOS, 2003). Daí ser possível compreender as ligações da ciência moderna com os grupos capitalistas dominantes, que fomentam a pesquisa científica com vistas à industrialização do conhecimento.

Impossível não se deter, nesta análise, frente ao discurso do desenvolvimento sustentável, que pretende compatibilizar crescimento econômico com preservação ambiental. Na concepção de Rodrigues 
(1998, p.57), "o conceito de desenvolvimento sustentável parece jogar uma cortina de fumaça sobre estas contradições, pois não propõe alterações nos modos de produzir e de pensar do modelo dominante". Para Altvater (1999, p. 146), "o desenvolvimento, na forma que predomina nos países altamente desenvolvidos, não é nem socialmente justo nem ecologicamente sustentável". É sintomático que a obsolescência artificial na indústria atinja, hoje, seu máximo grau em concomitância com o discurso da sustentabilidade. $\mathrm{Na}$ sociedade do descartável produzem-se cada vez mais mercadorias, que duram cada vez menos (RODRIGUES, 1998). “As mercadorias são transformadas para responder à modificação do gosto dos consumidores, gosto que é provocado e orientado por uma publicidade concebida cientificamente por psicossociólogos", na forma em que escreveu Labeyrie (2002, p. 126). Portanto, na exacerbação do consumo, podemos localizar uma das raízes da degradação ambiental.

Um programa de educação ambiental, minimamente adequado, exige também a abordagem das questões que dizem respeito à condição dos povos relativa à partilha dos recursos ambientais no contexto da economia ecológica mundial. A ecologia está mundializada, porém, como acusou Frémont (2002, p. 144), "a mundialização gera contrários".

A constatação de que a depleção dos recursos naturais realiza-se de maneira heterogênea entre as sociedades tradicionais e as sociedades industrializadas, ou, de outra forma, entre países pobres e países ricos, indica que a temática ambiental tem conotação variável e comporta, em grande medida, um forte conteúdo político e ideológico. Martine (1996, p. 13) esclarece que:

As sociedades pobres e tradicionais prejudicam o meio ambiente local de muitas maneiras, e vão prejudicá-lo ainda mais quando tiverem o dobro ou o triplo da população; mas, são os países industrializados que estão causando os problemas ambientais globais mais graves como o efeito estufa, o buraco na camada de ozônio, o esgotamento dos recursos naturais não-renováveis e a acumulação de lixo tóxico. (MARTINE, 1996, p.13).
As consequências do desajuste ambiental podem ser percebidas não apenas no buraco na camada de ozônio, no efeito estufa, nas alterações climáticas, na destruição das florestas tropicais e na extinção de espécies, mas, igualmente - e nisto reside sua maior perversidade - na exportação de resíduos tóxicos produzidos nos países ricos e depositados em países pobres (RODRIGUES, 1998), na transferência para os últimos de indústrias poluentes, as chamadas "indústrias sujas" (RODRIGUES, 1998; MARTINE, 1996), mantendo-se nos países ricos as indústrias consideradas "limpas".

O desajuste ambiental agrava-se em razão do rumo que tomou a dinâmica econômica mundial. Os países ricos, além de impor aos países não industrializados uma condição subalterna com base em trocas desiguais e no protecionismo (que caracteriza o sistema mundial de comércio) e na cobrança abusiva de juros de empréstimos com base em suas posições no interior do Fundo Monetário Internacional - FMI, e da Organização Mundial do Comércio - OMC -, os submetem a partir de políticas de liberalização e de desregulamentação, levando ao último grau o estado de miséria das massas (CHESNAIS, 1999). Chossudovsky (1999) vai além, aludindo a mecanismos de promoção e propagação da ideologia neoliberal, que corroboram o controle mundial, visando distorcer e encobrir as questões políticas referentes à pobreza e à proteção do ambiente nos países pobres.

Para Altvater (1999), a degradação ambiental deve ser tratada como assunto passível de regulamentação política e legal na legislação internacional, no âmbito dos direitos humanos e do direito dos povos. Parece impossível o estabelecimento de uma ordem mundial baseada na reciprocidade e na solidariedade no uso dos recursos e na assimilação de resíduos, "a não ser que o princípio de justiça global passe a predominar, fazendo com que também os países industrializados se enquadrem na redução necessária do nível de uso da natureza" (ALTVATER, 1999, p. 134). Afirma ainda que, em diversos países pobres, "ricos em matérias-primas, as riquezas em matérias-primas minerais ou agrárias não se transformam em aumento de renda e riqueza das respectivas populações" (ALTVATER, 1999, p. 134). Tais riquezas, em sua maior parte, são transferidas para os países industrializados, 
onde são transformadas em "riqueza industrial e apropriada por aqueles que dispõem do poder aquisitivo necessário, isto é, moeda forte no mercado mundial". Para o referido autor, as estratégias de desenvolvimento com base na extração de recursos nos países pobres mostraram-se, além de economicamente instáveis, negativas quanto ao desenvolvimento social, à estabilidade, à participação política e à integridade ecológica.

A maneira como foram estruturadas a ordem política e a dinâmica social no ocidente e se solidificaram as relações econômicas nos últimos séculos, faz com que os bens ambientais necessários para a produção e o consumo sejam reservados preferencialmente "a uma oligarquia que assegura seu acesso aos recursos por meios monetários" (ALTVATER, 1999, p. 146). As incoerências apresentadas pela economia ecológica mundial podem ser visualizadas a partir da constatação de que as populações que vivem em condições de subdesenvolvimento econômico têm menos direito de utilizar os recursos naturais do que os povos dos países ricos.

Entendida desta maneira, a problemática ambiental surge como manifestação de uma crise conjuntivamente tecida ao longo dos últimos séculos, assumindo, hoje, os contornos de uma crise da modernidade, de espectro mais abrangente, que pode ser percebida na política, na economia, na sociedade, na cultura e na ciência.

\section{CRISE DA MODERNIDADE E PROBLEMÁTI- CA AMBIENTAL}

A afirmação de que a modernidade está em crise é frequentemente repetida nos dias de hoje. De acordo com Habermas (1981), o projeto científico levado adiante a partir do século XVIII - o projeto da modernidade - foi, em grande medida, arquitetado pelos filósofos iluministas na busca de soluções para os grandes problemas que assolavam a humanidade na época, em um contexto de grande otimismo. Porém, o projeto da modernidade não se realizou por completo, de maneira que, a seu ver, permanecem inúmeros desajustes, entre os quais a problemática ambiental vem recebendo atenção especial, pois expõe a complexidade da sociedade contemporânea. E, por conseguinte, as contradições, oposições, complementaridades da política, da economia, e da cultura, nas diferentes escalas do espaço geográfico.

Diversos autores fazem, pois, alusão à crise da modernidade e procedem a seu diagnóstico, principalmente, a partir da identificação de seus sintomas, expressos no agravamento da problemática ambiental, nos desequilíbrios econômicos do capitalismo especulativo global, do sistema político ocidental falsamente representativo (cujos pleitos são, em princípio, reputados como democráticos, porém, os vencedores, em geral, são agentes do poder econômico), no avanço da ideologia neoliberal, de aumentos nos índices de desemprego e pobreza, inclusive nos países ricos etc.

Para alguns, há um sentimento de mal-estar diante do "sistema da racionalidade", que conduz ao questionamento da ciência, de seus métodos e de seu poder hegemônico. As avaliações desencadeadas em anos recentes incluem também a verificação dos padrões racionalistas, pretensamente científicos. De certo modo, está em xeque o valor explicativo de inúmeras teorias reputadas como científicas, ou seja, há uma carência de parâmetros que sirvam de base para explicações mais detalhadas da realidade. Portanto, está em jogo o poder da razão em assegurar o prosseguimento do projeto da modernidade, cuja legitimidade é constantemente posta em questão (GOMES, 1996).

Na interpretação de Fritjof Capra (1982), a mentalidade dominante na modernidade pode ser caracterizada pela crença de que o método científico é a única abordagem válida do conhecimento, na concepção do universo como sistema mecânico, na ideia de que a vida em sociedade demanda competitividade e que o crescimento econômico e tecnológico promoverá um progresso material sem limites. Para esse autor, tais ideias e valores, advindos da Revolução Científica, do Iluminismo e da Revolução Industrial, necessitam hoje de uma revisão radical.

Santos (2000) procura captar o sentido atual das transformações em curso como resultantes de um processo de transição que atinge todo o conjunto da sociedade a partir da constatação de que vivemos em uma sociedade intervalar, que se caracteriza, fundamentalmente, pela desconfiança sistemática face às evidências da nossa experiência imediata, pela total 
separação entre natureza e ser humano, pela aferição do rigor científico com base em parâmetros matemáticos e pelo determinismo mecanicista. A inadequação desse modelo, na atualidade, revela-se nos sintomas de crise da modernidade, não só de natureza social, ecológica e política, mas também na crise dos fundamentos sobre os quais se construiu o edifício da ciência moderna. Assim, supõe que os desdobramentos da crise e a transição em processo farão surgir um novo modelo de ciência - ao lado de transformações sociais, políticas e no âmbito do direito - em condições de promover a superação dos desequilíbrios promovidos pelo advento da modernidade. De seu ponto de vista, a intensificação da crítica ao racionalismo, ao empirismo e à ciência moderna, nas últimas décadas, fez emergir um conjunto de ideias que acenam para uma grande transformação em todos os campos do conhecimento.

$\mathrm{Na}$ concepção dominante ainda neste início do século XXI, desenvolvimento significa industrialização. Prevalece o pressuposto de que crescimento econômico e progresso tecnológico implicam, necessariamente, em desenvolvimento social, correlação que frequentemente não se manifesta. Além disso, está evidenciado que os avanços impingidos ao processo de industrialização opõem-se à preservação da natureza.

\section{PROBLEMÁTICA AMBIENTAL E CIÊNCIAS SOCIAIS}

A consideração adequada da questão ambiental, enquanto repercute de forma marcante no campo da educação, provoca, paralelamente, a ampliação do horizonte teórico no interior do qual vêm operando, há pelo menos dois séculos, as disciplinas acadêmicas. Esta transformação não se prende ao aspecto conceitual do termo "ambiente", pois, de fato, o aprofundamento da pesquisa, especialmente entre as ciências sociais, tem atestado a necessidade de supressão das reticentes barreiras entre os campos disciplinares. Neste contexto, a aproximação entre as disciplinas tem sido inevitável, até mesmo pelo fato de que algumas são historicamente próximas, a exemplo das disciplinas do grupo das ciências sociais.

A problemática ambiental não é, porém, o único campo de estudo que requer uma ampliação da abordagem. Tal como para outras problemáticas, como a questão agrária, a questão das metrópoles - em que ocorre imbricação de problemas dentro de um mesmo fenômeno -, na questão ambiental, o problema manifesta-se, a um só tempo, sob diversos aspectos, impossibilitando a dissecação e a classificação unitária dentro do espectro das disciplinas. Significa dizer que a questão ambiental envolve, simultaneamente, temas que dizem respeito a diversas áreas de estudo no quadro atual da organização dos saberes.

Os problemas ambientais são, inegavelmente, temas amplamente explorados entre as mais diversas disciplinas. Não sem razão Enrique Leff afirmou que "a crise ambiental é a crise de nosso tempo. O risco ecológico questiona o conhecimento do mundo". Esta crise também representa para nós, o "[...] limite do crescimento econômico e populacional; limite dos desequilíbrios ecológicos e das capacidades de sustentação da vida; limite da pobreza e da desigualdade social. Mas também crise do pensamento ocidental [...]" (LEFF, 2002, p. 191). A consideração dos aspectos naturais, que até poucas décadas era uma prerrogativa da Geografia (entre as ciências sociais), vem sendo gradativamente incorporada pelas demais disciplinas, a exemplo da Economia e da Sociologia. Em alguns casos, como o da Economia, por exemplo, "o fato de a corrente principal excluir o discurso ecológico passa a ser visto como ignorância por um número crescente de pessoas", como afirmou Altvater (1999, p. 113).

Para diversos economistas, atualmente, a atividade da qual participam só pode ser praticada a partir de uma perspectiva multidimensional e transdisciplinar, a exemplo de Passet (2002), para quem a Economia põe em relação a biosfera, a esfera econômica e a esfera humana, enfatizando que nenhum destes elementos pode ser apreendido independentemente dos outros. A economia "deve ser pensada no respeito das regulações da biosfera e dos imperativos humanos irredutíveis à sua própria lógica e, no entanto, indissociáveis dela própria; os bens livres não existem mais" (PASSET, 2002, p. 255).

Se pensarmos que há poucas décadas, "a base natural das economias em planejamento era considerada como infinita, isto é, como um fator de capital sem restrições de escassez" (MOTTA, 1997, p. 26), até mesmo a discussão sobre a temática da sustentabilidade, empreendida no campo da Economia, ainda que frequentemente carregada de um viés produtivista, 
admite, de antemão, o condicionamento da natureza em relação ao desenvolvimento. Sua abertura para as ciências naturais e para as demais ciências humanas tem se tornado notória nos dias de hoje.

Pode-se afirmar que a importância que vem tomando, nos últimos anos, os estudos de Sociologia ambiental no contexto das ciências sociais, representa uma alteração semelhante à que vem ocorrendo no campo da Economia. A valorização da questão ambiental no âmbito de uma disciplina que, historicamente, prescindiu da consideração da natureza, é um evento digno de nota. De fato, a questão ambiental não é o único campo em que os estudos sociológicos têm contemplado a natureza. O penetrante estudo de Goodman et al. (1990) parte exatamente da centralidade da natureza na explicação das peculiaridades da modernização da agricultura capitalista.

Na concepção de Wallerstein (1999), a divisão dos objetos de estudo nas ciências sociais remonta aos primeiros anos do século XIX, quando a investigação científica social foi estruturada sob domínio da ideologia liberal, que concebia Estado e mercado, política e sociedade como domínios analiticamente separáveis, cada qual com suas regras particulares. Seu protesto contra o modo de investigação predominante nas ciências sociais fundamenta-se na tese de que as três supostas áreas da ação humana - a econômica, a política e a social - não têm lógicas separadas.

O entrelaçamento de imposições, opções, decisões, normas e 'racionalidades'é tal que nenhum modelo útil de pesquisa pode isolar 'fatores' de acordo com as categorias do econômico, do político e do social e tratar apenas um tipo de variável mantendo implicitamente as outras constantes. Estamos dizendo que existe um único 'conjunto de regras' ou um único 'conjunto de imposições'dentro do qual essas várias estruturas operam. (WALLERSTEIN, 1999, p. 453).

Desse modo, a análise dos sistemas mundiais como a denomina Immanuel Wallerstein -, desconhece critérios que possam ser utilizados para estabelecer, de modo claro e defensável, as fronteiras entre as disciplinas do grupo das ciências sociais. Apesar da problemática ambiental não assumir uma centralidade na proposta de uma ciência social histórica, o modo como esta abordagem confronta a ordem tradicional dos saberes no âmbito das ciências sociais, abre um precedente para uma consideração ampla das relações sociedade-natureza.

François Dosse (2004) esclarece que a emergência da geo-história, nas primeiras décadas do século XX, decorreu justamente da valorização dos aspectos naturais em relação aos demais elementos, ainda que à custa da restrição do campo de ação dos geógrafos. De um ponto de vista histórico, Horácio Capel (1989) oferece uma contribuição valiosa na compreensão dos desenvolvimentos das diversas disciplinas que compõem as ciências sociais, quando esclarece que, desde o início, foram incorporados pela Geografia, problemas, métodos e teorias que originalmente tiveram origem no trabalho de economistas, cientistas políticos, antropólogos e sociólogos. Similarmente, da Geografia procederam contribuições que passaram a ser fundamentais no desenvolvimento dos demais campos disciplinares. Esta relação de reciprocidade, entre Geografia e as demais disciplinas do campo das ciências sociais, vem sendo, na atualidade, intensificada pela problemática ambiental.

Capel (1989) alude às preocupações com os problemas ecológicos, acrescentando-lhes a possibilidade de demolir a divisão entre Geografia física e Geografia humana, discussão que remonta à década de 1960. Diversas referências recentes podem ser encontradas em trabalhos publicados por geógrafos, a respeito deste caráter possivelmente catalisador de uma aproximação teórica, atribuído à problemática ambiental. Esta discussão pode ser encontrada, por exemplo, nas análises de Rodrigues (1998) e de Mendonça (2002). Para este último, a abordagem geográfica do ambiente "concebe a unidade do conhecimento geográfico como resultante da interação entre os diferentes elementos e fatores que compõem seu objeto de estudo" (MENDONÇA, 2002, p. 123).

Todavia, Capra (1982) afirma a impossibilidade de equacionamento das grandes questões do nosso tempo no âmbito de uma metodologia fragmentada, característica das nossas disciplinas acadêmicas. Problemas como a deterioração do ambiente, assim 
como a pobreza crônica dos países do "sul" requerem uma abordagem "sistêmica", pois estão intimamente interligados e são interdependentes. Não podem ser compreendidos a partir de um referencial restrito. Pelo contrário, pelo fato de serem complexos, exigem uma metodologia que possa contemplar sua complexidade.

Os avanços teóricos requeridos, evidentemente, constituir-se-ão a partir do questionamento da atual ordem dos saberes, implantada segundo os cânones do positivismo. As tarefas que se propõem, hoje, aos teóricos e pesquisadores, dizem respeito à necessidade de se elaborar uma abordagem que ultrapasse as barreiras entre as disciplinas, de se promover a superação da separação entre ciências sociais e ciências naturais, e de se oferecer uma explicação ampla, em condições de permitir uma intervenção precisa nos problemas ambientais.

Tendo em vista a necessidade de compreendermos a dimensão da problemática ambiental e suas repercussões na educação ambiental, e a percepção de que a humanidade deve aumentar a capacidade de controle e regulação das atividades econômicas, respeitando os limites impostos pela natureza, cabe-nos a tarefa de indagar que ações podem ser implementadas em favor de uma aproximação dos campos disciplinares.

A esse respeito, existem alguns pontos fundamentais sobre os quais alguns autores contemporâneos têm chamado a atenção, e que poderão balizar nossos trabalhos. A proposta de uma "ciência social histórica" elaborada por Wallerstein (1999), os debates em torno da complexidade levados adiante por Edgar Morin (2002) e as considerações de Boaventura de Sousa Santos (2000) acerca do padrão dominante na ciência moderna - para incluir apenas alguns trabalhos - sugerem uma mesma problemática: a fragmentação do conhecimento, que teve lugar no ocidente desde o início do processo de sistematização das ciências, tem impedido a consideração adequada das grandes questões do nosso tempo, e constitui-se, hoje, em uma barreira para o equacionamento teórico-metodológico da maioria das disciplinas acadêmicas.

\section{CONSIDERAÇÕES FINAIS}

O debate em torno da problemática ambiental vem sendo enriquecido, nos últimos anos, por contri- buições que têm origem em diversas áreas do conhecimento. Ao lado de biólogos, agrônomos, químicos, engenheiros e geógrafos, debruçados sobre um tema complexo, agora se juntam filósofos, economistas, sociólogos e outros estudiosos das ciências sociais.

Conforme foi discutido, parece claro que o debate acerca da temática ambiental deve abarcar uma ampla variedade de problemas, que penetram em todas as instâncias de análise. $\mathrm{O}$ enfrentamento desta questão, portanto, demanda um esforço proporcional à sua complexidade, pois persistem muitos desafios metodológicos no equacionamento dos problemas ambientais, associados às questões abordadas, de passagem, neste texto.

Em vista disso, parece útil sugerir a discussão da questão ambiental a partir da aproximação dos campos disciplinares, o que tornaria possível tanto a junção, para o mesmo propósito, das disciplinas do grupo das ciências sociais, como de algumas do grupo das ciências naturais. Porém, esta proposta deve ser discutida e testada e, se aqui a expusemos, o fizemos com a intenção de estimular a discussão.

Não obstante, esta discussão parece não ter chegado a um dos campos centrais de sua aplicação - a educação ambiental, nas escolas de nível fundamental e médio -, ou, se chegou, o fez de uma maneira muito limitada, de modo que, em geral, evita-se ligar a problemática ambiental a outros temas tidos como espinhosos, como, por exemplo, a política. Provavelmente, esta restrição na abordagem está relacionada com a própria política educacional e, de forma mais ampla, ao "papel regulador" que desempenha a escola, em alta desde a aplicação das medidas neoliberais no ensino público.

Os esforços pedagógicos que se concentram na explicação da dinâmica dos ciclos biogeoquímicos e dos ecossistemas apresentados apenas sob a perspectiva biológica, assim como a simples descrição dos impactos ambientais promovidos pela ação antrópica, promovem, sim, efeitos positivos na sensibilização dos educandos a respeito dos sintomas da crise ambiental. Contudo, se mostram pouco eficazes na operacionalização de mudanças estruturais na ordem econômica, social e política vigente.

Nosso ponto de vista é o de que não é possível atingir os objetivos que estão colocados à 
educação ambiental se uma ampliação temática não for efetivada. Em outras palavras, é necessário, sim, abordar nesta discussão, os aspectos sociais, políticos e ideológicos envolvidos, o que poderá resultar num questionamento a respeito das funções da escola.

A possibilidade de que a ação popular venha desempenhar um papel importante no destino do planeta também deve ser considerada. As possibilidades estão abertas para uma efetiva intervenção das massas no futuro ambiental do planeta. Ainda que o processo de globalização tenha promovido um desmantelamento da capacidade pública de controlar a degradação ambiental, bem como de amenizar os problemas sociais, como o desemprego e a pobreza, novas estruturas de governança estão emergindo, em substituição às funções tradicionais do Estado. O protesto popular, o boicote a produtos e empresas, a ação das associações de bairro, a participação das organizações não governamentais (ONGs), os movimentos ambientalistas, os movimentos sociais e demais organizações da chamada sociedade civil surgem como possibilidades de participação popular de grande importância (ALTVATER, 1999). Além disso, o voto popular em favor de um comprometimento com a preservação ambiental não deixa de ser crucial.

Cremos ser desnecessário reprisar o papel que os professores têm a cumprir neste processo, especialmente na promoção de discussões em sala de aula, em torno dos aspectos envolvidos na questão ambiental, quais sejam, os de natureza política, geopolítica, social e ideológica. É preciso, talvez mais do que nunca, que haja uma ampliação da abordagem no trato da questão ambiental.

\section{REFERÊNCIAS}

ALTVATER, E. Os desafios da globalização e da crise ecológica para o discurso da democracia e dos direitos humanos. In: HELLER, A. et al. A crise dos paradigmas em ciências sociais e os desafios para o século XXI. Rio de Janeiro: Contraponto, 1999. p. 109-153.

CAPEL, H. Geografia humana y ciencias sociales: una perspectiva histórica. 2. ed. Barcelona: Montesinos, 1989.
CAPRA, F. O ponto de mutação. Tradução de Álvaro Cabral. São Paulo: Cultrix, 1982.

CHESNAIS, F. Um programa de ruptura com o neliberalismo. In: HELLER, A. et al. A crise dos paradigmas em ciências sociais e os desafios para o século XXI. Rio de Janeiro: Contraponto, 1999. p. 77-108.

CHOSSUDOVSKY, M. A globalização da pobreza: impactos das reformas do FMI e do Banco Muncial. São Paulo: Moderna, 1999.

DOSSE, F. História e Ciências Sociais. Tradução de Fernanda Abreu. Bauru: EDUSC, 2004.

FRÉMONT, A. O planeta solidário. In: MORIN, E. (Org.). A religação dos saberes: o desafio do século XXI. Tradução de Flávia Nascimento. 3. ed. Rio de Janeiro: Bertrand Brasil, 2002. p. 140 - 144.

GOMES, Paulo César da Costa. Geografia e modernidade. Rio de Janeiro: Bertrand Brasil, 1996.

GOODMAN, D.; SORJ, B.; WILKINSON, J. Da lavoura às biotecnologias: agricultura e indústria no sistema internacional. Tradução de Carlos Eduardo Baesse de Souza e Carlos Schiottfeldt. Rio de Janeiro: Campus, 1990.

HABERMAS, J. La modernité: un projet inachevé. Critique, Paris, v. XXXVII, n. 413, 1981. p. 950-967.

LABEYRIE, V. As conseqüências ecológicas das atividades tecno-industriais. In: MORIN, E. (Org.). A religação dos saberes: o desafio do século XXI. Tradução de Flávia Nascimento. 3. ed. Rio de Janeiro: Bertrand Brasil, 2002. p. 125-139.

LEFF, E. Epistemologia ambiental. 2. ed. Tradução de Sandra Valenzuela. São Paulo: Cortez, 2002.

MARTINE, G. (Org.). População, meio ambiente e desenvolvimento: verdades e contradições. 2. ed. Campinas: UNICAMP, 1996.

MENDONÇA, F. Geografia socioambiental. In: 
MENDONÇA, F.; KOZEL, S. (Orgs.). Elementos de epistemologia da geografia contemporânea. Curitiba: UFPR, 2002. p. 121-144.

MORIN, E. (Org.). A religação dos saberes: o desafio do século XXI. Tradução de Flávia Nascimento. 3. ed. Rio de Janeiro: Bertrand Brasil, 2002.

MOTTA, R. S. A questão econômica da questão ambiental. In: SHIKI, S. SILVA, G.; ORTEGA, J.; CÉSAR, A. (Orgs). Agricultura, meio ambiente $e$ sustentabilidade do cerrado brasileiro. Uberlândia: EDUFU, 1997. p. 25-31.

PASSET, R. Economia: da unidimensionalidade à transdiciplinaridade. In: MORIN, E. (Org.). A religação dos saberes: o desafio do século XXI. Tradução de Flávia Nascimento. 3. ed. Rio de Janeiro: Bertrand Brasil, 2002. p. $251-256$.
RODRIGUES, A. M. Produção e consumo do e no espaço: problemática ambiental urbana. São Paulo: HUCITEC, 1998.

SANTOS, B. S. A crítica da razão indolente: contra o desperdício da experiência, 2. ed., São Paulo: Cortez, 2000.

Cortez, 2003.

SORRE, M. A adaptação ao meio climático e biossocial - Geografia psicológica. Tradução de Maria Cecília França. In: . Geografia. MEGALE, F. J. (Org.). São Paulo: Ática, 1984.

WALLERSTEIN, Immanuel. Análise dos sistemas mundiais. In: GIDDENS, A.; TURNER, J. (Org). Teoria social hoje. Tradução de Gilson César C. de Sousa. São Paulo: UNESP, 1999. p. 447-470. 